\title{
BMJ Open Disparities between research attention and burden in liver diseases: implications on uneven advances in pharmacological therapies in Europe and the USA
}

\author{
Nambi Ndugga, ${ }^{1}$ Teisha G Lightbourne, ${ }^{2}$ Kavon Javaherian, ${ }^{2}$ Joaquin Cabezas, ${ }^{1}$ \\ Neha Verma, ${ }^{2}$ A Sidney Barritt IV, ${ }^{1}$ Ramon Bataller ${ }^{1}$
}

To cite: Ndugga N, Lightbourne TG, Javaherian $\mathrm{K}$, et al. Disparities between research attention and burden in liver diseases: implications on uneven advances in pharmacological therapies in Europe and the USA. BMJ Open 2017;7:e013620. doi:10.1136/bmjopen-2016013620

- Prepublication history and additional material is available. To view please visit the journal (http://dx.doi.org/ 10.1136/bmjopen-2016013620)

Received 29 July 2016 Revised 5 January 2017 Accepted 2 February 2017

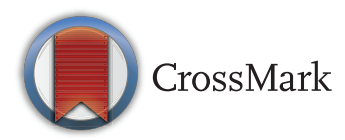

${ }^{1}$ Divisions of Gastroenterology and Hepatology, Chapel Hill, North Carolina, USA ${ }^{2}$ Biochemistry, Departments of Medicine and Nutrition, Gillings School of Global Public Health, University of North Carolina at Chapel Hill, Chapel Hill, North Carolina, USA

Correspondence to Ramon Bataller;

bataller@med.unc.edu

\section{ABSTRACT}

Objectives: Effective oral therapies for hepatitis $B$ and $C$ have recently been developed, while there are no approved pharmacological therapies for alcoholic and non-alcoholic fatty liver diseases (ALD and NAFLD). We hypothesise that fewer advances in fatty liver diseases could be related to disparities in research attention.

Methods: We developed the Attention-to-Burden Index $(\mathrm{ABI})$ that compares the research activities during 2010-2014, and an estimate of disease burden of these 4 major liver diseases. The resulting ratio reflects either overattention (positive value) or inadequate attention (negative value) compared with disease burden. The mean research attention and disease burden were calculated from 5 and 6 different parameters, respectively. The efficacy rate of current pharmacological therapies was assessed from published clinical trials.

Findings: The mean research attention for hepatitis $B$ and $\mathrm{C}$ was $31 \%$ and $47 \%$, respectively, while NAFLD and ALD received $17 \%$ and $5 \%$. The overall burden was $5 \%$ and $28 \%$ for hepatitis B and C, and $17 \%$ and $50 \%$ for NAFLD and ALD. The calculated ABI for hepatitis $B$ and $C$ revealed $a+6.7$-fold and +1.7 -fold overattention, respectively. NAFLD received an appropriate attention compared with its burden, while ALD received marked inadequate attention of -9.7fold. The efficacy rate of current pharmacological agents was $72 \%$ for hepatitis B, $89 \%$ for hepatitis C, $25 \%$ for non-alcoholic steatohepatitis and $13 \%$ for alcoholic hepatitis. Importantly, we found a positive correlation between the mean attention and the efficacy rate of current therapies in these 4 major liver diseases.

Interpretation: There are important disparities between research attention and disease burden among the major liver diseases. While viral hepatitis has received considerable attention, there is a marked inadequate attention to ALD. There is a critical need to increase awareness of ALD in the liver research community.

\section{Strengths and limitations of this study}

- This is the first comprehensive systematic study assessing the relative attention to the major liver diseases.

- This study develops a novel tool to estimate the ratio between the research attention and burden of major liver disease (ie, the Attention-toBurden Index or $\mathrm{ABI}$ )

- We found a strong correlation between the efficacy of current pharmacological therapies and the degree of research attention devoted to each major liver disease, which strongly suggests the need to reallocate more research resources to alcoholic liver disease.

- The global burden of the major liver disease is largely unknown and we used an array of different variables.

- The efficacy of pharmacological therapies for viral hepatitis can be easily calculated based on viral parameters, while the parameters to evaluate the resolution of fatty liver diseases are not well established.

\section{INTRODUCTION}

Liver diseases are a major cause of morbidity and mortality. ${ }^{1}$ The main causes include chronic viral hepatitis $\mathrm{B}$ (HBV) and $\mathrm{C}$ (HCV), as well as alcoholic and nonalcoholic fatty liver diseases (ALD and NAFLD, respectively). The role of these causes on the burden of liver disease depends on disease severity and on geographical factors. In global north countries such as France, fatty liver diseases (NAFLD, ALD or its combination) account for most cases of liver fibrosis while $\mathrm{HBV}$ is highly prevalent in Asian countries. ${ }^{2} 3$ Regarding advanced liver disease, ALD is the main cause of cirrhosis worldwide, accounting for $50 \%$ of the cases. ${ }^{4}$ In Europe and the USA, 
stark increases in morbidity due to alcohol-associated liver disease have been observed in the past 15 years. ${ }^{5}{ }^{6}$ Importantly, the role of NAFLD as a cause of advanced liver disease and hepatocellular carcinoma has markedly increased in many countries due to the epidemics of diabetes and obesity. ${ }^{7}$

Major advances have been made in the management of viral hepatitis, such as vaccines and oral therapies for $\mathrm{HBV}$, and oral regimes for $\mathrm{HCV}^{8}{ }^{9}$ In the past decade, there has been an increased focus on NAFLD, with studies identifying targeted therapies and subsequent clinical trials. ${ }^{10}{ }^{11}$ In comparison to the advances, ALD has been afforded scant attention, with few advances in its management. ${ }^{12}$ Patients with ALD are mostly identified at late stages of the disease, and programmes for early detection are scarce. Moreover, the genetic and environmental factors are largely unknown.

We hypothesised that differences in advancement between viral hepatitis and fatty liver diseases, in particular ALD, are related to varying allocations of research resources. There are no systematic studies assessing the relative research on different aetiologies of liver disease, or how commensurate research attention is with disease burden. The current study was undertaken to fill this gap.

\section{METHODS}

\section{General design}

For this systematic analysis, data on the research attention were obtained at multiple levels for the four main liver disease aetiologies, carried out during the years 2010-2014, and analysed during 2015. The aetiologies categorised were HCV, HBV, NAFLD and ALD, while data on less prevalent liver diseases were considered but not included in the final analysis. A quantitative scoring system was used to define and subsequently measure research attention to liver disease aetiology. When a single cause of liver disease was identified in a presentation, grant, clinical trial or scientific publication, full points (1.0 point) were allocated to the disease. When two causes of liver disease were identified, points were equally shared ( 0.5 point each). When the focus of a study could be attributed to more than two causes of liver disease or the study investigated a common mechanism (eg, hepatocellular apoptosis) and/or consequence of liver diseases (eg, ascites), the finding was excluded. Basic science studies that investigated common mechanisms of liver disease were also excluded.

\section{Quantification of research attention}

The relative level of attention to each liver disease was calculated at five different levels: primary research presented at major scientific liver meetings, drugs in development, research opportunities, clinical trials and publications. The mean research attention was calculated by averaging the relative level of attention devoted to each liver disease in each of the five categories.
Major scientific liver meetings

The scoring system for the two major global liver scientific meetings (American Association Study of Liver Diseases (AASLD) and European Association for the Study of the Liver (EASL)) was designed to reflect the quantity of presentations as well as the level of presentation. The scores were allocated as follows: 5 points, title of a large symposium (eg, postgraduate course); 4 points, title of small courses or joint workshops; 3 points, scientific presentations at an oral general meeting or plenary session, presidential lectures or state-of-the-art lectures and titles of parallel session; 2 points, scientific presentations at a parallel session, early morning workshops, meet-the-professor luncheon or grand rounds and titles from sections of the poster presentations; and 1 point, scientific presentation as a poster. The number of abstracts in each category was multiplied by the allocated score to provide an overall weighted research attention. Only clinical and translational studies including human samples were included. Scores for attention are reported as a percentage or total $\mathrm{N}$.

\section{Drugs in development}

A systematic online search of the 38 major pharmaceutical companies was made to determine the amount of pharmacological therapies in development for the four major liver diseases. Drugs in development that were specifically indicated for one of the four liver diseases were included in the analysis.

\section{Research opportunities}

The National Institutes of Health (NIH) Research Portfolio Reporting Tools (RePORTER) was accessed to identify public funding opportunities in the USA. The following Boolean searches were performed using these terms: 'alcoholic liver disease' excluding 'non-alcoholic fatty liver disease', 'hepatitis $\mathrm{C}$ virus', 'hepatitis B virus', 'nonalcoholic fatty liver disease' excluding 'alcoholic liver disease'. To identify public grant opportunities for the European Union (EU), the Community Research and Development Information Service (CORDIS) advanced search database was used, and the 'Only Projects' tab was selected and the same search items were entered. The number of corresponding grants was recorded by disease category.

\section{Clinical trials and scientific publications}

The same search terms used for the research opportunities section were entered into Clinicaltrials.gov and PubMed to identify ongoing clinical trials and publications, respectively. Observational and interventional ongoing studies for the four major liver diseases were identified. Trials and/or publications on unspecific liver diseases (ie, cirrhosis) were excluded.

\section{Estimation of disease burden}

We estimated the burden of each of the four main liver diseases by combining parameters indicative of early and 
advanced liver disease as well as hospitalisation costs. The following parameters were used to estimate the relative burden of each of the major four liver diseases: (1) liverrelated mortality in the USA ${ }^{13}$ (2) causes of liver fibrosis estimated by non-invasive tests; ${ }^{14}$ (3) causes of liver cirrhosis; ${ }^{15}$ (4) cause of liver transplantation in the USA and the EU. The causes of liver transplantation in Europe were identified from the European Liver Transplantation Registry. To account for patients with concurrent aetiologies (eg, HCV/ALD), we divided the number of patients with HCV/ALD and assigned half of them to HCV and half of them to ALD. ${ }^{16}{ }^{17}$ (5) Inpatient hospitalisation costs of patients with liver disease in the USA. ${ }^{18}$ (6) Hospital admissions and discharges: the data were obtained from the total number of patient discharges for each of the four main liver diseases. ${ }^{18}$

\section{Estimation of rate of efficacy of current pharmacological therapies}

We conducted a systematic review of the main controlled clinical trials testing targeted therapies for viral hepatitis and fatty liver diseases. Studies published during the period 2010-2014 in the most cited journals were included and reviewed. For HBV, the cure rate was determined by DNA clearance or persistent reduction of Hepatitis B Surface Antigen (HBsAg). For HCV, we considered the sustained viral response (SVR) at 12 weeks to help determine drug efficacies. In patients with biopsyproven non-alcoholic steatohepatitis (NASH), we defined drug efficacy as histological improvement of patients in the NAFLD Activity Score (NAS) score and/or fibrosis. Regarding ALD, in the absence of consistent studies in patients with early disease, rates of efficacy were based on 28-day survival in patients with alcoholic hepatitis (AH).

\section{Development of the Attention-to-Burden Index}

The Attention-to-Burden Index (ABI) was developed to compare the research activities during 2010-2014, and an estimate of disease burden of the four major liver diseases. The ABI for each liver disease was calculated as the mean research attention divided by the mean disease burden for each liver disease. A resulting ratio close to 1 reflects an appropriate attention compared with the burden. In contrast, ABI reflects either overattention (positive value) or inadequate attention (negative value) compared with the burden.

\section{Statistical analysis}

Descriptive data are reported for liver meeting attention, drug development attention, published article attention, clinical trial attention, research grant attention and burden of disease as either $\mathrm{N}$ or per cent where appropriate. Ratios were created comparing the proportion of disease attention and proportion of disease burden. SPSS software (Chapel Hill, North Carolina, USA) was used to determine the Pearson's correlation between drug efficacy and research attention to the four main liver diseases. An analysis of variance test was also carried out to determine the level of significance of the correlation between research attention and pharmaceutical drug efficacy.

\section{RESULTS}

Analysis of research attention to major liver diseases (2010-2014)

We first performed a systematic analysis of the research attention paid to the four main liver diseases during the period 2010-2014 at five different levels. EASL meetings had a research attention of $55 \%$ and $25 \%$ for $\mathrm{HCV}$ and HBV, respectively, while NAFLD and ALD received $13 \%$ and $7 \%$, respectively. AASLD meetings provided similar research focus to HCV and HBV (attentions of $49 \%$ and 32\%, respectively) while NAFLD and ALD received $14 \%$ and $4 \%$ (figure 1A, table 1 and online supplementary table S1).

In the analysis of drugs in the pipeline from the main 38 drug companies, we found 74 drugs specifically indicated to treat these four major liver diseases. Eighty-two per cent of such drugs were for HCV, mainly oral-acting interferon-free regimes. A smaller proportion of drugs were devoted to HBV (12\%), while only $6 \%$ of the drugs in development were focused on treating either NAFLD (3\%) or ALD (3\%; see online supplementary table S2). Next, research opportunities were assessed in public agencies in the USA and the EU (see online supplementary table S3). In the USA and the EU, it was found that the majority of funding opportunities were devoted to HCV ( $48 \%$ and $61 \%$, respectively), followed by HBV ( $21 \%$ and $30 \%$; figure $1 \mathrm{~B}$ ). In contrast, NAFLD received less attention (20\% in the USA and $7 \%$ in the EU) while ALD received minimal funding opportunities ( $3 \%$ in the USA and $0 \%$ in the EU). Next, registered clinical trials were analysed to determine the proportion of focus devoted to the four main liver diseases. A total of 1273 clinical trials were found, and most studies were devoted to test anti-HCV and HBV drugs $(32 \%$ and $36 \%$, respectively; figure 1C). The proportion of ongoing trials for NAFLD was $5 \%$, while $18 \%$ of ongoing trials were specifically devoted to ALD (table 2). These differences were similar when the clinical trials were divided between interventional and observational trials (data not shown). Finally, the relative number of scientific publications devoted to different types of liver diseases was analysed for the period 2010 2014. A total of 39093 publications were found on the four main liver diseases included in our study. Published studies for HCV and HBV accounted for $46 \%$ and $32 \%$, respectively (figure 1D). The publications for NAFLD were lower at $17 \%$, and for ALD, even more so at $5 \%$. Overall, the mean research attention afforded to the four main liver diseases was greater for $\mathrm{HCV}$ and $\mathrm{HBV}$ at $47 \%$ and $31 \%$, respectively, than it was for NAFLD and $\mathrm{ALD}$ at $17 \%$ and $5 \%$, respectively (figure 2 ).

Estimation of disease burden for the major liver diseases In the absence of systematic studies assessing the burden of the major liver disease worldwide, we next estimated 
Figure 1 Parameters of research attention to the four major liver diseases. The relative level of attention devoted to each liver disease from different parameters: $(A)$ detailed analysis of all presentations at the two major annual scientific liver meetings (AASLD and EASL); (B) research opportunities offered by public agencies in the USA and in the $\mathrm{EU} ;(\mathrm{C})$ ongoing registered clinical trials (ClinicalTrials.gov); (D) scientific publications (PubMed). AASLD, American Association Study of Liver Diseases; $\mathrm{AH}$, alcoholic hepatitis; ALD, alcoholic liver disease; EASL, European Association for the Study of the Liver; EU, European Union; HBV, hepatitis B virus; $\mathrm{HCV}$, hepatitis $\mathrm{C}$ virus; NAFLD, non-alcoholic fatty liver disease; $\mathrm{NASH}$, non-alcoholic steatohepatitis; $\mathrm{NIH}$, National Institutes of Health.

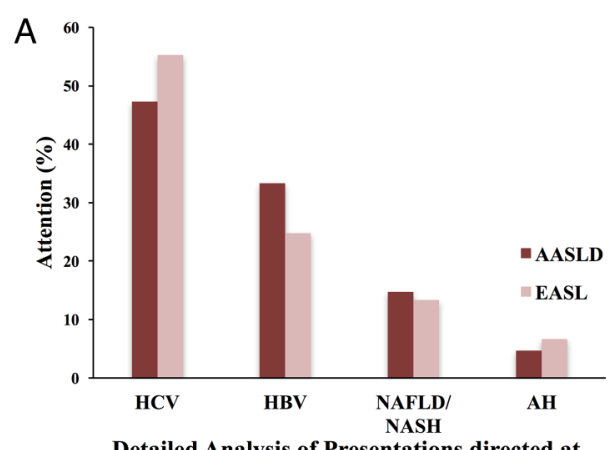

Detailed Analysis of Presentations directed at the 4 Main Liver Diseases at AASLD and

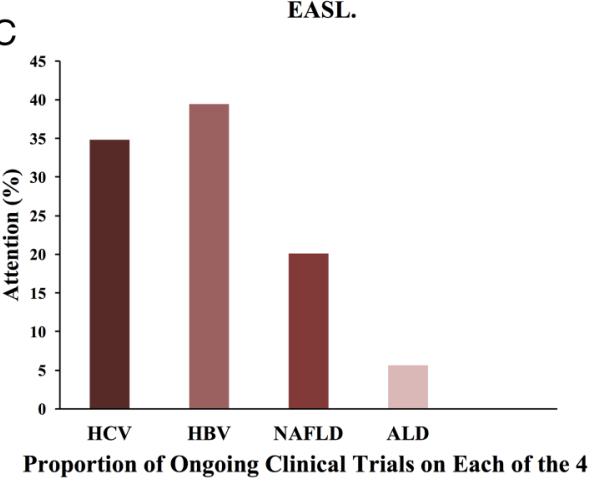
Main Liver Diseases from Clinical Trials.org

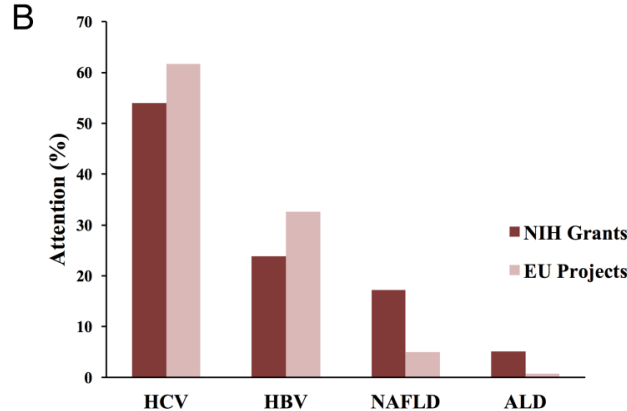

Amount of Research Opportunities offered by Public Agencies to the 4 Main Liver Diseases.

D

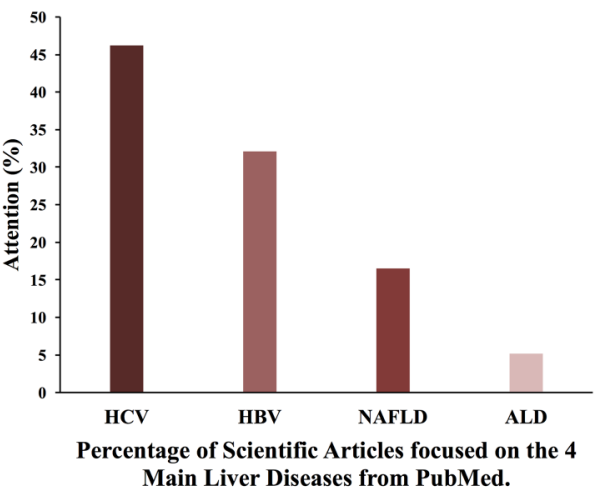

the overall burden of the four major liver diseases by combining data from six different parameters (see methods). The relative numbers of mortality caused by liver disease in the USA can be attributed to $23 \% \mathrm{HCV}$, $0.54 \%$ to HBV, $3 \%$ to NAFLD and $50 \%$ to ALD. ${ }^{13}$ The indications of liver fibrosis in the USA were $10 \%$ to $\mathrm{HCV}, 7 \%$ to $\mathrm{HBV}, 48 \%$ to NAFLD and $35 \%$ to ALD. ${ }^{14}$ The causes of liver cirrhosis in the USA were $47 \%$ to $\mathrm{HCV}, 3 \%$ to HBV, $27 \%$ to NAFLD and $25 \%$ to ALD. ${ }^{15}$ The main indications of liver transplantation in the EU and the USA were attributed as $28 \%$ and $40 \%$ to HCV, $11 \% \mathrm{HBV}(\mathrm{EU})$, in the USA there were no data on HBV due to its low indication rate for transplantation, $10 \%$ and $16 \%$ to NAFLD, and $39 \%$ and $23 \%$ to ALD. ${ }^{16} 17$ HCV and HBV contributed to \$167 785 million (15\%) and $\$ 52062(5 \%)$ of hospitalisation costs, while NAFLD and ALD contributed to $\$ 45755(4 \%)$ and $\$ 848189$ $(76 \%)$, respectively, in the USA. ${ }^{18}$ The relative number of hospital admissions and discharges were obtained from Peery et $a l \mathrm{~s}^{18}$ calculation of the burden of gastrointestinal disease in the USA in 2012, and were attributed to the four aetiologies of liver disease: at 14749 $(17 \%)$ and $4568(5 \%)$ to HCV and HBV, and at 2858 (3\%) and $64752(74 \%)$ to NAFLD and ALD (see online

Table 1 Weighted research attention to main liver diseases in the two most attended international liver conferences, 20102014

\begin{tabular}{|c|c|c|c|c|c|c|c|c|}
\hline \multicolumn{9}{|l|}{ Weighted values } \\
\hline International Liver Conference & EASL & AASLD & EASL & AASLD & EASL & AASLD & EASL & AASLD \\
\hline Symposia* & 277.5 & 47.5 & 92.5 & 49.5 & 35 & 10 & 25 & 15 \\
\hline Titles of sessions $†$ & 144 & 278 & 100 & 164 & 50 & 110 & 42 & 44 \\
\hline Oral—general presentations $\ddagger$ & 78 & 43.5 & 21 & 13.5 & 27 & 6 & 3 & 3 \\
\hline Oral-parallel presentations§ & 33 & 54 & 26 & 39 & 13 & 20 & 11 & 16 \\
\hline Poster presentation & 945.5 & 1708 & 423.5 & 1135 & 231 & 475.5 & 98.5 & 135 \\
\hline Total weighted points & 1478 & 2131 & 663 & 1401 & 356 & 621.5 & 179.5 & 213 \\
\hline \multicolumn{9}{|c|}{$\begin{array}{l}\text { *Incidence multiplied by } 5 \text { research points. It includes courses, joint workshops and industry-supported satellite symposia. } \\
\text { tIncidence multiplied by } 4 \text { research points. It includes titles of entire oral parallel session and poster categories. } \\
\text { łlncidence multiplied by } 3 \text { research points. It includes plenary sessions, presidential lectures, state-of-the-art lectures and European Liver } \\
\text { Patients Association (ELPA) workshops. } \\
\text { \$lncidence multiplied by } 2 \text { research points. It includes early morning workshops, meet-the-professor luncheons and grand rounds. } \\
\text { Ilncidence multiplied by } 1 \text { research point. } \\
\text { AASLD, American Association for the Study of the Liver; ALD, alcoholic liver disease; EASL, European Association for the Study of Liver } \\
\text { Diseases; HBV, hepatitis B virus; HCV, hepatitis C virus; NAFLD, non-alcoholic fatty liver disease. }\end{array}$} \\
\hline
\end{tabular}


Table 2 Research attention from clinical trials, public agencies and PubMed

\begin{tabular}{|c|c|c|c|c|}
\hline & HCV (n, \%) & HBV & NAFLD & ALD \\
\hline Drugs in development & $61(82)$ & $9(12)$ & $2(3)$ & $2(3)$ \\
\hline EASL & $1478(55)$ & $663(25)$ & $356(13)$ & $179.5(7)$ \\
\hline AASLD & $2131(49)$ & 1401 (32) & $621.5(14)$ & $135(5)$ \\
\hline PubMed & 15438 (39) & $10724(27)$ & $5518(14)$ & $1728(4)$ \\
\hline NIH grants & $738(48)$ & $328(21)$ & $300(20)$ & $47(3)$ \\
\hline EU grants & $52.5(61)$ & $25.5(30)$ & $6(7)$ & $0(0)$ \\
\hline Clinical trials & 407 (32) & $461(36)$ & $66(5)$ & 235 (18) \\
\hline Mean research attention & $47 \%$ & $31 \%$ & $17 \%$ & $5 \%$ \\
\hline
\end{tabular}

supplementary table S4). Taking into account all these parameters, the mean disease burden was calculated at $28 \%$ and $5 \%$ for HCV and HBV, respectively, and $17 \%$ and $50 \%$ for NAFLD and ALD (figure 3 ).

\section{Relative research attention compared with disease burden (ABI)}

In order to critically analyse if there are disparities between the attention that the liver research community pays to the major liver disease and their burden, we generated $\mathrm{ABI}$ (if the relative attention equals the relative burden of a given liver disease, the ratio should be 1 ).

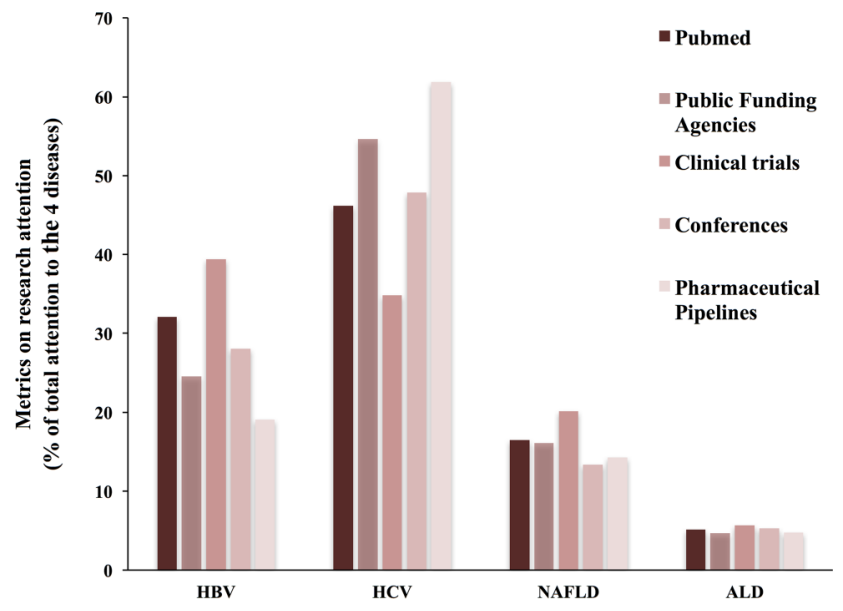

Figure 2 Calculation of mean research attention to the four major liver diseases. The mean research attention to the four main liver diseases (HBV, HCV, NAFLD and ALD) was calculated from five parameters: scientific publications (PubMed); research opportunities offered by public agencies in the USA and the EU; ongoing registered clinical trials (ClinicalTrials.gov); detailed analysis of all presentations at the two major annual scientific liver meetings (AASLD and EASL); and number of drugs in development in the pipeline of 38 major pharmaceutical companies. AASLD, American Association Study of Liver Diseases; ALD, alcoholic liver disease; EASL, European Association for the Study of the Liver; EU, European Union; HBV, hepatitis B virus; HCV, hepatitis $C$ virus; NAFLD, non-alcoholic fatty liver disease.
The calculated ABI for hepatitis $\mathrm{B}$ and $\mathrm{C}$ revealed a +6.7 -fold and +1.7-fold overattention, respectively. NAFLD received an ABI of -1.2 -fold, reflecting its recent rise in attention within the field of hepatology, while ALD received a marked inadequate attention of -9.7-fold (figure 4 and table 3). The ABI indicates that while viral hepatitis has been extensively studied during the past years, ALD is being markedly overlooked.

\section{Efficacy rate of current therapies: correlation with the degree of research attention}

Finally, we hypothesised that there is a relationship between the degree of research attention to each major liver disease and the therapeutic advances. In order to address this question, we conducted a systematic review of the main controlled clinical trials testing targeted therapies for viral hepatitis and fatty liver diseases. For $\mathrm{HBV}$ and HCV, we determined the efficacy in terms of sustained viral response. In patients with biopsy-proven NASH, we defined drug efficacy as histological improvement of patients in the NAS and/or fibrosis. Regarding ALD, there are no consistent clinical trials to test targeted therapies in patients with early/compensated forms. Therefore, we focus on the efficacy of drugs in improving short-term survival in patients with $\mathrm{AH}$. Following these criteria, the efficacy rate of current pharmacological agents was $72 \%$ for $\mathrm{HBV}, 89 \%$ for $\mathrm{HCV}$, $25 \%$ for $\mathrm{NASH}$ and $13 \%$ for $\mathrm{AH}$ (figure $5 \mathrm{~A}$ and see online supplementary table S5). Importantly, there was a positive relationship between the mean attention to each major liver disease and the success rate of pharmacological therapies (figure 5B). This figure strongly suggests that the greater the concentration of research on one liver disease, the more likely to develop efficacious drugs. ${ }^{18-46}$

\section{DISCUSSION}

In the past decade, major advances have been achieved in the field of viral hepatitis, with the development of highly active oral antiviral therapies. In clear contrast, there are no approved therapies for NAFLD and ALD 
Figure 3 Estimation of mean disease burden to four main liver diseases. The mean disease burden to the four main liver diseases (HBV, HCV, NAFLD and ALD) was calculated from seven parameters: total number of US hospitals discharged, US hospitalisation costs, OLTY-EU, OLTY-US, cirrhosis-US, fibrosis and US mortality. ALD, alcoholic liver disease; HBV, hepatitis $B$ virus; $\mathrm{HCV}$, hepatitis $\mathrm{C}$ virus; NAFLD, non-alcoholic fatty liver disease.

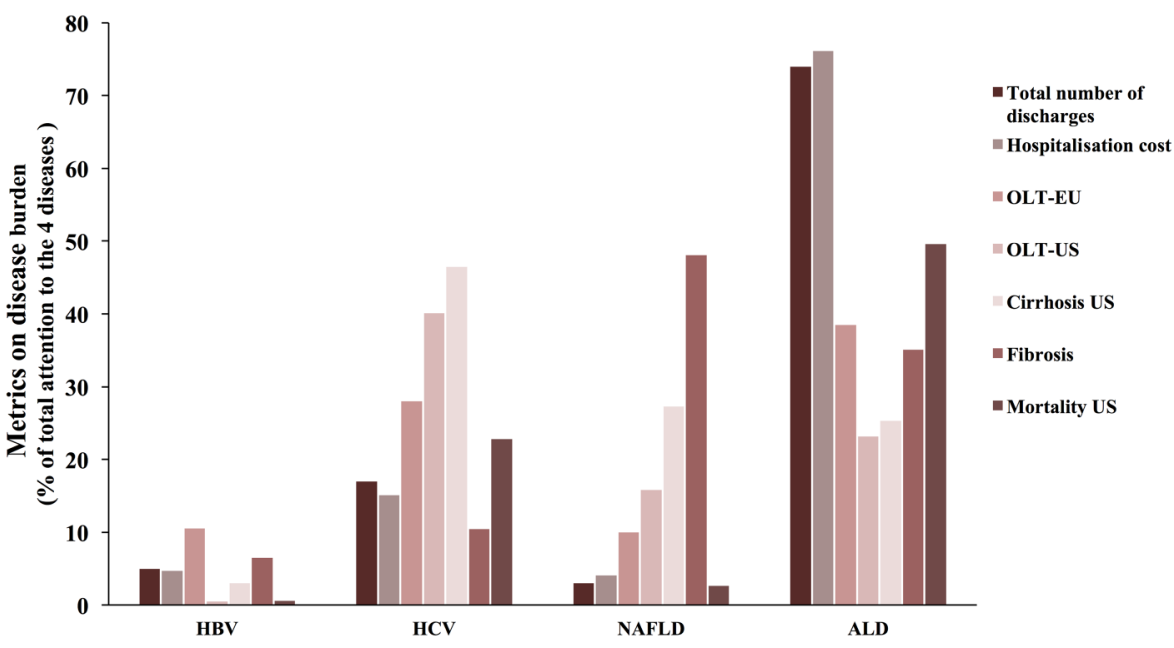

and interventions for $\mathrm{AH}$ are largely unchanged over the past $40+$ years. We hypothesised that these discrepant advances are related to unequal allocation of research resources. Our systematic study found marked disparities between research attention and disease burden among the aetiologies of liver disease. We compared multiple modalities of hepatology research attention (eg, scientific meeting presentations, research funding, drugs under development, funding opportunities and publications) with measures of liver disease burden (prevalence, fibrosis and healthcare costs). We found a lack of correlation between research attention and disease burden. Overall, viral hepatitis received a 5-7-fold overattention, while alcoholic liver disease received a 10-fold underattention. There are a few similar studies in other fields of medicine that have investigated research attention and disease burden. ${ }^{47}$ Using a similar methodology to ours, these studies used clinicaltrials.gov, while others compared NIH funding to disease burden. Unfortunately, the discrepancy between funding and burden has become a common theme.
The finding of attention-burden discordance is most likely multifactorial. HBV and HCV are causes of cirrhosis and hepatocellular carcinoma, and are important public health issues in their own right. ${ }^{1}{ }^{2}$ Therapeutic targets for viral hepatitis are better defined than those for fatty liver diseases (eg, proteins regulating viral replication), and there is a significant interest to develop antiviral agents. It is important to recognise that the nature of these diseases also plays an important role in the development of drug therapies. The pathways of viral hepatitis (HBV and HCV) diseases have a significant positive effect on the advancement of effective drug therapies compared with that of fatty liver diseases. HBV and HCV have clear aetiologies, with transmission of the virus occurring in determined pathways which provide scientific researchers with clear targets for the development of pharmacotherapies. In contrast, fatty liver diseases (NAFLD and ALD) have multiple causes and are linked to other health conditions, their complex aetiologies, which necessitate the development of therapies that address multiple targets, and may contribute to the lack of drugs targeted to NAFLD or ALD.
Figure $4 \quad A B I$ for the four major liver diseases. $A B I$ was calculated using the ratio of mean research attention (comprising different parameters shown in figure 1) to mean disease burden (comprising the parameters shown in figure 2) of the four main liver diseases. $A$ value $>1$ reflects overattention compared with the disease burden, while a value $<1$ reflects inadequate attention. $\mathrm{ABI}$, Attention-to-Burden Index ALD, alcoholic liver disease; HBV, hepatitis $B$ virus; $\mathrm{HCV}$, hepatitis $\mathrm{C}$ virus; NAFLD, non-alcoholic fatty liver disease.

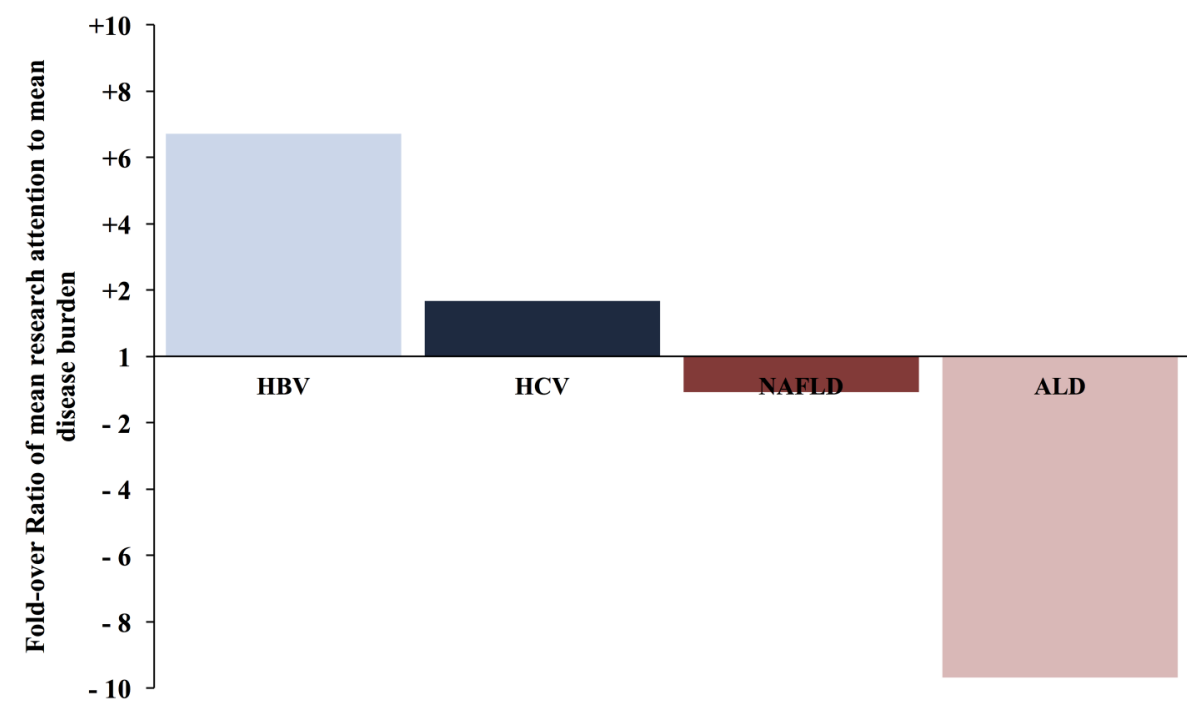


Table 3 Attention to Burden Index

\begin{tabular}{lllll}
\hline & HBV & HCV & NAFLD & ALD \\
\hline Mean research attention & $29 \%$ & $51 \%$ & $15 \%$ & $5 \%$ \\
Mean disease burden & $5 \%$ & $28 \%$ & $17 \%$ & $50 \%$ \\
Ratio & 6.71 & 1.67 & 0.93 & 0.10 \\
Fold-over ratio & 6.71 & 1.67 & -1.08 & -9.68 \\
Attention-to-Burden Score & $\mathbf{6 . 7 1}$ & $\mathbf{1 . 7}$ & $\mathbf{- 1 . 1}$ & $\mathbf{- 9 . 7}$
\end{tabular}

The Attention-to-Burden score is bolded to highlight it. It is the final score that was calculated that informed the Attention Burden Index.

ALD, alcoholic liver disease; HBV, hepatitis B virus; HCV, hepatitis $C$ virus; NAFLD, non-alcoholic fatty liver disease.

It is observed that increases in attention become selfperpetuating, with scientific advances (ie, drug development efforts, research allotment, etc) influencing greater research attention (more presentations, drugs, funding opportunities and publications) and vice versa. The inadequate attention especially to ALD is complex and includes the social stigma surrounding alcoholism, poorly defined targets for therapy, a lack of good animal models, few non-invasive markers of severity and poor general awareness of the diseases. Additionally, there is a lack of large-scale early detection efforts, and thus patients are often identified at very late stages of the disease. These challenges alongside patient identification, research and therapy result in a high burden of disease.

Our findings should be viewed as a comparative assessment of relative attention and burden among the major liver diseases. While we completed an extensive search, which expanded over a 5-year period and involved multiple areas within both the public and private sectors, our estimates were derived from pre-existing databases with their own respective inclusion and exclusion criteria. Thus, limitations of this study include the possibility of incomplete estimates. Other limitations include the inability to complete a systematic review of the global burden of the major liver diseases due to the limited number of articles that focus on fatty liver disease burdens. The limited and heterogeneous resources used for burden estimates reflect the need for further research.

Consequences of this large discrepancy among hepatitis and fatty liver diseases include extraordinary advances in the therapy of HCV and HBV prevention, while little advancements in early detection and treatment of ALD and NAFLD have been made. It is unknown if these differences impact mortality. The next decade could benefit from greater research attention being allocated to NAFLD and ALD. Translational studies identifying targets for therapy for fatty liver disease will certainly encourage pharmaceutical companies to invest in clinical trials. Ultimately, efforts by public funding agencies and the scientific community to address the diseases with the greatest public health burden will result in improved health outcomes for the greatest number of people.

A striking finding of our study is the minimal attention that both public and private sources pay to ALD, which is the main cause of cirrhosis globally. ${ }^{4}$ In recent years, a concurrent increase in addiction behaviour and the prevalence of resulting illnesses such as ALD has been observed in the USA and Europe. ${ }^{56}$ Accompanying the sharp rise in ALD cases is the increasing burden of patients with liver disease on national health systems, identifying them as the main group expenditures in patient hospitalisation costs. ${ }^{18}$ In spite of its significant health and socioeconomic burden, few major advances have been made in the management of patients with ALD. The pharmacological therapies used today have not changed since 1971 (ie, prednisolone for $\mathrm{AH}$ ), and no widespread early detection programmes have been developed. ${ }^{48}$ Our study should increase awareness in the public health agencies and academic institutions, especially in Europe, to devote more resources to face this
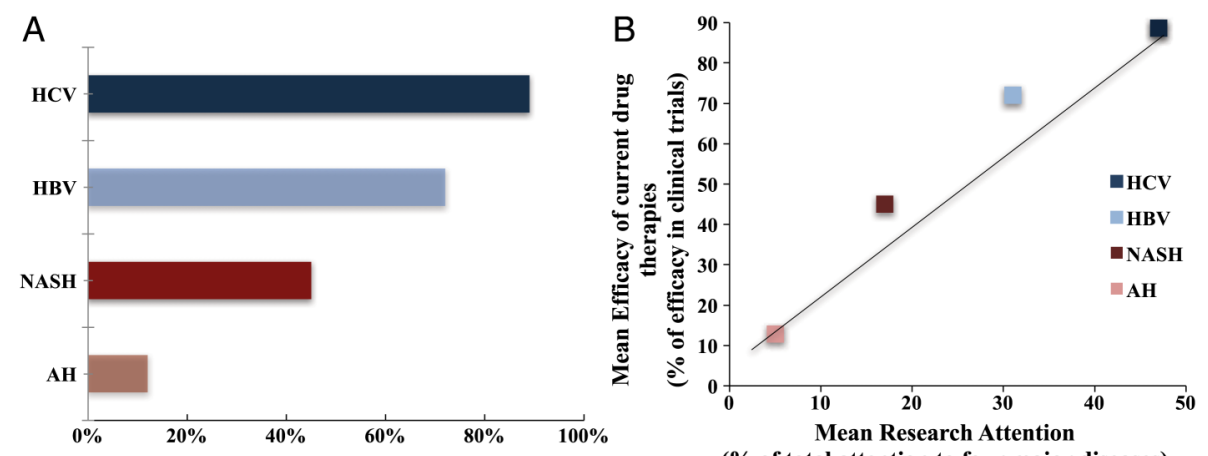

(\% of total attention to four major diseases)

Figure 5 Correlation between the efficacy of current drug therapies for hepatitis and the mean research attention. (A) Current mean rate of efficacy for therapeutic drugs; $(B)$ correlation between the efficacy of current drug therapies for hepatitis and the mean research attention. The efficacy of current drug therapies to treat chronic hepatitis (HCV), chronic hepatitis B (HBV), NASH and $\mathrm{AH}$ was calculated based on large published clinical trials (see Methods section). Definition criteria of drug efficacy for each of the four type of hepatitis were: HCV: sustained viral response at 12 weeks; HBV: achievement of end points suppressing viral replication; NASH: reduction in NAS or fibrosis score; $\mathrm{AH}$ : effect on short-term mortality rate. AH, alcoholic hepatitis; HBV, hepatitis B virus; HCV, hepatitis C virus; NAS, NAFLD Activity Score; NASH, non-alcoholic steatohepatitis. 
prevalent and devastating liver disease. The development of a European Agency for Alcohol Studies, similar to the National Institute for Alcohol and Alcoholism (NIAAA) in the USA, seems a timely initiative.

Contributors NN participated in the collection and analysis of data on disease burden, efficacy of current pharmacological therapies, as well as in the interpretation of data, writing, critical revision and final approval of the manuscript. TGL participated in the collection of data from drug companies, ongoing clinical trials, as well as in the analysis of data and final approval of the manuscript. KJ participated in the collection of all data from major liver meetings (EASL and AASLD), analysis of data and final approval of the manuscript. JC participated in the statistical analysis, data presentation and interpretation, and the final approval of the manuscript. NV participated in the data collection and analysis of the published papers on each liver disease, and final approval of the manuscript. ASB participated in the conception and design of the work, and critical revision and final approval of the manuscript. RB participated in the conception and design of the work, data interpretation, drafting of the article and critical revision and final approval of the manuscript.

Funding This work was supported by a grant from NIAAA (1U01AA021908). Competing interests None declared.

Provenance and peer review Not commissioned; externally peer reviewed.

Data sharing statement Additional data are available by emailing the corresponding author at bataller@med.unc.edu.

Open Access This is an Open Access article distributed in accordance with the Creative Commons Attribution Non Commercial (CC BY-NC 4.0) license, which permits others to distribute, remix, adapt, build upon this work noncommercially, and license their derivative works on different terms, provided the original work is properly cited and the use is non-commercial. See: http:// creativecommons.org/licenses/by-nc/4.0/

\section{REFERENCES}

1. Mokdad AA, Lopez AD, Shahraz S, et al. Liver cirrhosis mortality in 187 countries between 1980 and 2010: a systematic analysis. BMC Med 2014;12:145.

2. Poynard T, Deckmyn O, Munteanu M, et al. Awareness of the severity of liver disease re-examined using software-combined biomarkers of liver fibrosis and necroinflammatory activity. BMJ Open 2015;5:e010017.

3. Wang FS, Fan JG, Zhang Z, et al. The global burden of liver disease: the major impact of China. Hepatology 2014;60:2099-108.

4. Poznyak V, Rekve D. Global status report on alcohol and health 2014. World Health Organization, 2014.

5. Case A, Deaton A. Rising morbidity and mortality in midlife among white non-Hispanic Americans in the 21st century. Proc Natl Acad Sci USA 2015;112:15078-83.

6. Williams R, Ashton K, Aspinall R, et al. Implementation of the lancet standing commission on liver disease in the UK. Lancet 2015;386:2098-111.

7. Younossi ZM, Koenig AB, Abdelatif D, et al. Global epidemiology of non-alcoholic fatty liver disease-meta-analytic assessment of prevalence, incidence and outcomes. Hepatology 2016;64:73-84.

8. Martin $\mathrm{P}$, Lau DT, Nguyen $\mathrm{MH}$, et al. A Treatment algorithm for the management of chronic hepatitis $B$ virus infection in the United States: 2015 update. Clin Gastroenterol Hepatol 2015;13:2071-87. e16.

9. Zoulim F, Liang TJ, Gerbes AL, et al. Hepatitis C virus treatment in the real world: optimising treatment and access to therapies. Gut 2015;64:1824-33.

10. Hardy T, Anstee QM, Day CP. Nonalcoholic fatty liver disease: new treatments. Curr Opin Gastroenterol 2015;31:175-83.

11. Satapathy SK, Sanyal AJ. Epidemiology and natural history of nonalcoholic fatty liver disease. Semin Liver Dis 2015;35:221-35.

12. Mathurin $P$, Bataller R. Trends in the management and burden of alcoholic liver disease. J Hepatol 2015;62(Suppl 1):S38-46.

13. Asrani SK, Larson JJ, Yawn B, et al. Underestimation of liver-related mortality in the United States. Gastroenterology 2013;145:375-82. e1-2.
14. Roulot D, Costes JL, Buyck JF, et al. Transient elastography as a screening tool for liver fibrosis and cirrhosis in a community-based population aged over 45 years. Gut 2011;60:977-84.

15. Scaglione S, Kliethermes S, Cao G, et al. The epidemiology of cirrhosis in the United States: a population-based study. J Clin Gastroenterol 2015;49:690-6.

16. Adam R, Karam V, Delvart V, et al. Evolution of indications and results of liver transplantation in Europe. A report from the European Liver Transplant Registry (ELTR). J Hepatol 2012;57:675-88.

17. Wong RJ, Aguilar M, Cheung R, et al. Nonalcoholic steatohepatitis is the second leading etiology of liver disease among adults awaiting liver transplantation in the United States. Gastroenterology 2015;148:547-55.

18. Peery AF, Dellon ES, Lund J, et al. Burden of gastrointestinal disease in the United States: 2012 update. Gastroenterology 2012;143:1179-87. e1-3.

19. Akriviadis E, Botla R, Briggs W, et al. Pentoxifylline improves short-term survival in severe acute alcoholic hepatitis: a double-blind, placebo-controlled trial. Gastroenterology 2000;119:1637-48.

20. Altamirano J, Bataller R. Alcoholic liver disease: pathogenesis and new targets for therapy. Nat Rev Gastroenterol Hepatol 2011:8:491-501.

21. Andreone P, Colombo MG, Enejosa JV, et al. ABT-450, ritonavir, ombitasvir, and dasabuvir achieves $97 \%$ and $100 \%$ sustained virologic response with or without ribavirin in treatment-experienced patients with HCV genotype $1 \mathrm{~b}$ infection. Gastroenterology 2014;147:359-65. e1.

22. Au JS, Pockros PJ. Novel therapeutic approaches for hepatitis C Clin Pharmacol Ther 2014;95:78-88.

23. Bugianesi E, Gentilcore E, Manini R, et al. A randomized controlled trial of metformin versus vitamin $\mathrm{E}$ or prescriptive diet in nonalcoholic fatty liver disease. Am J Gastroenterol 2005;100:1082-90.

24. Chang TT, Gish RG, de Man R, et al. A comparison of entecavir and lamivudine for $\mathrm{HBeAg}$-positive chronic hepatitis B. N Engl J Med 2006;354:1001-10.

25. Charlton M, Everson GT, Flamm SL, et al. Ledipasvir and sofosbuvir plus ribavirin for treatment of $\mathrm{HCV}$ infection in patients with advanced liver disease. Gastroenterology 2015;149:649-59.

26. Forrest E, Mellor J, Stanton L, et al. Steroids or pentoxifylline for alcoholic hepatitis (STOPAH): study protocol for a randomised controlled trial. Trials 2013;14:262.

27. Hézode C, Asselah T, Reddy KR, et al. Ombitasvir plus paritaprevir plus ritonavir with or without ribavirin in treatment-naive and treatment-experienced patients with genotype 4 chronic hepatitis $C$ virus infection (PEARL-I): a randomised, open-label trial. Lancet 2015;385:2502-9.

28. Kowdley KV, Lawitz E, Poordad F, et al. Phase $2 \mathrm{~b}$ trial of interferon-free therapy for hepatitis $\mathrm{C}$ virus genotype 1. $\mathrm{N}$ Engl J Med 2014;370:222-32.

29. Lai CL, Gane E, Liaw YF, et al. Telbivudine versus lamivudine in patients with chronic hepatitis B. N Engl J Med 2007;357: 2576-88.

30. Lavine JE, Schwimmer JB, Van Natta ML, et al. Effect of vitamin E or metformin for treatment of nonalcoholic fatty liver disease in children and adolescents: the TONIC randomized controlled trial. JAMA 2011;305:1659-68.

31. Lawitz E, Sulkowski MS, Ghalib R, et al. Simeprevir plus sofosbuvir, with or without ribavirin, to treat chronic infection with hepatitis $C$ virus genotype 1 in non-responders to pegylated interferon and ribavirin and treatment-naive patients: the COSMOS randomised study. Lancet 2014;384:1756-65.

32. Manns M, Pol S, Jacobson IM, et al. All-oral daclatasvir plus asunaprevir for hepatitis $C$ virus genotype $1 \mathrm{~b}$ : a multinational, phase 3, multicohort study. Lancet 2014;384:1597-605.

33. Marcellin P, Heathcote EJ, Buti M, et al. Tenofovir disoproxil fumarate versus adefovir dipivoxil for chronic hepatitis B. $N$ Engl J Med 2008;359:2442-55.

34. Mathurin P, Louvet A, Duhamel A, et al. Prednisolone with vs without pentoxifylline and survival of patients with severe alcoholic hepatitis: a randomized clinical trial. JAMA 2013;310:1033-41.

35. Molina JM, Orkin C, Iser DM, et al. Sofosbuvir plus ribavirin for treatment of hepatitis $C$ virus in patients co-infected with HIV (PHOTON-2): a multicentre, open-label, non-randomised, phase 3 study. Lancet 2015;385:1098-106.

36. Moreno $\mathrm{C}$, Langlet $\mathrm{P}$, Hittelet $\mathrm{A}$, et al. Enteral nutrition with or without $\mathrm{N}$-acetylcysteine in the treatment of severe acute alcoholic hepatitis: a randomized multicenter controlled trial. $J$ Hepatol 2010;53:1117-22. 
37. Nguyen-Khac E, Thevenot T, Piquet MA, et al. Glucocorticoids plus $\mathrm{N}$-acetylcysteine in severe alcoholic hepatitis. N Engl J Med 2011;365:1781-9.

38. Phillips $\mathrm{M}$, Curtis $\mathrm{H}$, Portmann $\mathrm{B}$, et al. Antioxidants versus corticosteroids in the treatment of severe alcoholic hepatitis-a randomised clinical trial. J Hepatol 2006;44:784-90.

39. Ratziu V, Sheikh MY, Sanyal AJ, et al. A phase 2 , randomized, double-blind, placebo-controlled study of GS-9450 in subjects with nonalcoholic steatohepatitis. Hepatology 2012;55:419-28.

40. Roth D, Nelson DR, Bruchfeld A, et al. Grazoprevir plus elbasvir in treatment-naive and treatment-experienced patients with hepatitis $C$ virus genotype 1 infection and stage 4-5 chronic kidney disease (the C-SURFER study): a combination phase 3 study. Lancet 2015;386:1537-45.

41. Sanyal AJ, Chalasani N, Kowdley KV, et al. Pioglitazone, vitamin E, or placebo for nonalcoholic steatohepatitis. $N$ Engl J Med 2010;362:1675-85.
42. Thursz MR, Richardson P, Allison M, et al. Prednisolone or pentoxifylline for alcoholic hepatitis. $N$ Engl $J$ Med 2015;372:1619-28.

43. Trépo C, Chan HL, Lok A. Hepatitis B virus infection. Lancet 2014;384:2053-63.

44. Van Wagner LB, Koppe SW, Brunt EM, et al. Pentoxifylline for the treatment of non-alcoholic steatohepatitis: a randomized controlled trial. Ann Hepatol 2011;10:277-86.

45. Zein CO, Yerian LM, Gogate P, et al. Pentoxifylline improves nonalcoholic steatohepatitis: a randomized placebo-controlled trial. Hepatology 2011;54:1610-19.

46. Zeuzem S, Soriano V, Asselah T, et al. Faldaprevir and deleobuvir for HCV genotype 1 infection. N Engl J Med 2013;369:630-9.

47. Gillum LA, Gouveia C, Dorsey ER, et al. NIH disease funding levels and burden of disease. PLOS ONE 2011;6:e16837.

48. Mandrekar P, Bataller R, Tsukamoto $\mathrm{H}$, et al. Alcoholic hepatitis: translational approaches to develop targeted therapies. Hepatology 2016;64:1343-55. 